\title{
Is there an association between vitamin $D$ deficiency and adenotonsillar hypertrophy in children with sleep-disordered breathing?
}

\author{
Ji-Hyeon Shin ${ }^{*}$ (D, Byung-Guk Kim, Boo Young Kim, Soo Whan Kim, Sung Won Kim and Hojong Kim
}

\begin{abstract}
Background: Low vitamin D levels have been linked to the risk of sleep-disordered breathing (SDB) in children. Although adenotonsillar hypertrophy (ATH) is the major contributor to childhood SDB, the relationship between ATH and serum vitamin D is uncertain. We therefore investigated the relationship between vitamin D levels and associated factors in children with ATH.

Methods: We reviewed data from all children with SDB symptoms who were treated from December 2013 to February 2014. Of these, 88 children whose serum vitamin D levels were measured were enrolled in the study. We divided the children into four groups based on adenoidal and/or tonsillar hypertrophy. We conducted a retrospective chart review to analyze demographic data, the sizes of tonsils and adenoids, serum 25-hydroxy-vitamin D [25(OH)D] level, body mass index (BMI), and allergen sensitization patterns.

Results: Children in the ATH group had a lower mean 25(OH)D level than did those in the control group $(p<0.05)$. Children with vitamin D deficiencies exhibited markedly higher frequencies of adenoidal and/or tonsillar hypertrophy than did those with sufficient vitamin $D(p<0.05)$. Spearman's correlation analysis identified an inverse correlation between serum 25(OH)D levels and age, tonsil and adenoid size, and height (all $p<0.05$ ). In a multiple regression analysis, tonsil and adenoid size as well as BMI-z score, were associated with 25(OH)D levels after controlling for age, sex, height, and mite sensitization $(p<0.05)$.

Conclusions: Our results suggest that low vitamin D levels are linked to ATH. Both the sizes of the adenoids and tonsils and the BMI-Z score were associated with the 25(OH)D level. Therefore, measurement of the serum 25(OH)D level should be considered in children with ATH and SDB symptoms.
\end{abstract}

Keywords: Vitamin D, Adenoids, Tonsils, Sleep-disordered breathing, Body mass index, Child

\section{Background}

The spectrum of sleep-disordered breathing (SDB) is characterized by snoring, mouth-breathing, and pauses in breathing. SDB includes primary snoring, upper airway resistance syndrome, obstructive sleep apnea (OSA), and obstructive hypoventilation. Children with SDB not only experience sleep disturbances, but also neurocognitive impairment and attention problems.

\footnotetext{
*Correspondence: tachyon0217@gmail.com; shinjee79@catholic.ac.kr Department of Otolaryngology-Head and Neck Surgery, College of Medicine, The Catholic University of Korea, 222 Banpo-daero, Seocho-gu, Seoul 06591, Republic of Korea
}

Adenotonsillar hypertrophy (ATH), the primary cause of OSA, is a common childhood disease that can be surgically treated [1-4].

Vitamin D, a fat-soluble vitamin, is synthesized in the skin upon exposure to sunlight and is also obtained from foods. Low vitamin D levels have been linked to many risk factors, including obesity, limited exposure to sunlight, prematurity, malabsorption, darkly pigmented skin, aging, chronic use of steroids or anticonvulsants, and low socioeconomic status [5-7]. In addition, several studies have reported that vitamin D deficiency may increase the risk of numerous acute/chronic otorhinolaryngologic 
conditions, including allergic rhinitis, chronic rhinosinusitis with nasal polyps, recurrent otitis media, acute respiratory infections, asthma, and benign paroxysmal positional vertigo [8-13].

Chronically low vitamin D levels may also be associated with sleep disorders [14, 15]. Recent studies reported that low vitamin D levels were related to OSA, and that continuous positive airway pressure treatment increased vitamin D levels in adults with OSA $[16,17]$. Vitamin D deficiency has been linked to increases in the sizes of the tonsils and/or adenoids and thus to OSA development [18-20]. A decrease in vitamin D levels after an inflammatory insult has also been reported [21, 22], as has an association of low vitamin D levels and adenotonsillar diseases [23, 24]. In contrast, other studies found no association between serum vitamin D levels and such diseases $[25,26]$. As the principal cause of vitamin D deficiency is inadequate exposure to sunlight, these conflicting results may be explained by differences in latitude and seasonal variations among studies. In addition, differences in ethnicity and skin color may also be in play [27-29].

In the present study, all subjects lived at the same latitude, were of the same ethnic group, and were evaluated only during winter, therefore reducing potential variations attributable to differences in the abovementioned factors. Our aim was to measure vitamin D levels and analyze associated factors in children with SDB.

\section{Methods}

\section{Subjects}

We conducted a retrospective cross-sectional study at a single, university-based, secondary referral hospital. We recruited all children with SDB symptoms (e.g., snoring, mouth- breathing, paused breathing, and excessive daytime sleepiness) who were treated from December 2013 to February 2014.

In 2012, the authors established critical pathways for the clinical management of SDB, which state that the work up for SDB includes a physical examination, lateral plain X-ray of the nasopharynx, a quality of life evaluation using the Korean version [30] of the obstructive sleep apnea (KOSA)-18 survey [31], allergy evaluation, and measurement of the serum vitamin $\mathrm{D}$ level at our outpatient clinic.

The inclusion criteria of the present study were: (1) age 4-12 years; (2) habitual snoring, observed apnea, and/or mouth- breathing during sleep at least 1 year in duration; (3) total KOSA-18 score $\geq 60$ (4) evaluation of atopic status using the multiple allergen simultaneous test (MAST); and (5) 25-hydroxy-vitamin D [25(OH)D] level measurement. The exclusion criteria were: (1) any craniofacial anomaly; (2) any anatomical abnormality, including nasal septal deviation, turbinate hypertrophy, and/or nasal polyps; (3) a recent history of nasal or upper airway infection; (4) malnutrition; (5) the use of vitamin D supplements or multivitamin agents; (6) a history of adenoidectomy and/or tonsillectomy; and/or (7) the use of anti-inflammatory and/or anti-allergic drugs within 4 weeks prior to enrollment.

We retrieved demographic, height, body weight, body mass index (BMI), BMI z-score, tonsil and adenoid size, atopic status, and serum vitamin D level data from medical records. We analyzed retrospectively collected data without collecting blood samples by our research group. We described the methods for in vitro IgE sensitization testing and measurement of serum vitamin D levels to clarify how these measurements have been obtained.

BMI was the body weight $(\mathrm{kg})$ divided by the height squared $\left(\mathrm{m}^{2}\right)$. We used the Korean national 2007 growth charts to determine BMI z-scores.

Tonsillar hypertrophy (TH) was graded using the Brodsky scale [32], as follows: grade 0 (tonsils situated in the tonsillar fossa); grade 1 (tonsils just outside of the tonsillar fossa and occupying $\leq 25 \%$ of the airway); grade 2 (tonsils occupying $26-50 \%$ of the airway); grade 3 (tonsils occupying $51-75 \%$ of airway); and grade 4 (tonsils occupying $>75 \%$ of the airway). We used the adenoidal-nasopharyngeal ratio (ANR,) obtained from a lateral plain X-ray of the nasopharynx, to represent the adenoidal size. The depths of the adenoids and nasopharynx were measured using the standard landmarks of Fujioka [33]. The adenoids were measured by drawing lines perpendicular to lines drawn along the straight region of the anterior margin of the basiocciput to the point of maximal adenoidal convexity. The nasopharynx was measured by drawing a line from the anterior inferior edge of the sphenobasioccipital synchondrosis to the posterior superior margin of the hard palate. The ANR was then determined by dividing the first measurement by the second.

We defined grade 3 or 4 tonsils as TH. We defined an ANR $\geq 0.8$ as indicative of adenoidal hypertrophy (AH). We then divided the children into four groups: control, $\mathrm{AH}, \mathrm{TH}$, and $\mathrm{ATH}$.

\section{The Korean version of the obstructive sleep apnea (KOSA)-18}

To assess quality of life, caregivers completed the KOSA-18 questionnaire, a disease-specific questionnaire validated in Korea. The 18 items of the KOSA-18 are grouped within five domains (sleep disturbance, physical symptoms, emotional distress, daytime function, and caregiver concerns) and are scored using a 7-point ordinal scale, followed by summing of the scores. Possible scores range from 18 to 126 points, with a higher score indicating a worse quality of life. Franco et al. suggested a clinical classification based on the OSA-18, with scores $<60$ suggesting a small impact on the health-related 
quality of life, scores between 60 and 80 a moderate impact, and scores $>80$ a large impact [31]. According to this classification, we used the KOSA-18 as one of the inclusion criteria and children with total scores of $\geq 60$ were included in this study.

\section{Determination of serum 25-hydroxy-vitamin D levels}

To evaluate vitamin D status, serum levels of 25-hydroxyvitamin $\mathrm{D}(25(\mathrm{OH}) \mathrm{D})$ were measured using a direct competitive chemiluminescence immunoassay (CLIA; LIAISON $^{\circ} 25 \mathrm{OH}$ vitamin D assay; DiaSorin, Saluggia, Italy). The intra- and interassay coefficients of variation for $25(\mathrm{OH}) \mathrm{D}$ were $3-6$ and $7-11 \%$, respectively.

\section{Sensitization patterns of the allergens}

In vitro IgE sensitization testing was carried out using the multiple allergen simultaneous test (MAST) (RoboScreen $^{\text {twx; }}$ Bee Robotics Ltd., Gwynedd, UK). The panel consists of 39 allergens, including foods, tree/grass/weed pollens, fungi, dogs, cats, cockroaches, and house dust mites. A score $\geq 2$ was interpreted as positive [34].

\section{Statistical analysis}

Statistical analyses were performed using SPSS for Windows software (ver. 15.0; SPSS, Inc., Chicago, IL). Qualitative parameters were evaluated with a chi-square test, and quantitative parameters using a Kruskal-Wallis test. Factors associated with vitamin D deficiency were evaluated using Spearman's correlation test. For multivariate analysis, a multiple regression analysis was used. All statistical tests were two-tailed. A $P$-value $<0.05$ was considered to indicate statistical significance.

\section{Ethics statement}

Written informed consent was not obtained because of the retrospective nature of the study. However, the study protocol was approved by our Institutional Review Board (IRB policy NO. UC15RISI0035).

\section{Results}

We included 88 patients [59 males $(67.0 \%)$ and 29 females (33.0\%)] of mean age $8.9 \pm 2.5$ years. The mean serum $25(\mathrm{OH}) \mathrm{D}$ level was $19.4 \pm 5.1 \mathrm{ng} / \mathrm{mL}$. A serum $25(\mathrm{OH}) \mathrm{D}$ level $<20 \mathrm{ng} / \mathrm{mL}$ was considered to reflect a vitamin D deficiency [35]; 52.3\% of the children were deficient. The frequency of $\mathrm{AH}$ and/or $\mathrm{TH}$ in children with vitamin $\mathrm{D}$ deficiency and sufficiency was 91.3 and $71.4 \%$, respectively. Deficient children exhibited markedly higher frequency rates of $\mathrm{AH}$ and/or $\mathrm{TH}$ than did those exhibiting vitamin sufficiency $(p=0.035$, Fig. 1$)$.

\section{Children with ATH had lower 25(OH)D levels}

We compared the clinical characteristics of the control, $\mathrm{AH}, \mathrm{TH}$, and ATH groups. The numbers of children per group were as follows: control, 16 (18.2\%); $\mathrm{AH}, 18$ (20.4\%); TH, 19 (21.6\%), and ATH, 35 (39.8\%). The children in the ATH group were younger than those in the $\mathrm{AH}$ group $(p=0.021)$. The ATH group had more females than the control and $\mathrm{AH}$ groups $(p=0.002$ and 0.042 , respectively). We found no significant difference in height, body weight, BMI, or BMI z-score among the four groups (Table 1). The mean serum 25(OH)D levels of the four groups were as follows: control, $22.5 \pm 4.3$; $\mathrm{AH}, 18.7 \pm 6.5 ; \mathrm{TH}, 19.4 \pm 4.5$; and $\mathrm{ATH}, 18.4 \pm 4.5 \mathrm{ng} /$ $\mathrm{mL}$. The children in the ATH group had the lowest mean 25(OH)D level (i.e., lower than that of the control group [ $p=0.01$, Fig. 2]).

\section{Allergen sensitization}

A comparison of the atopic status among the four groups showed that the mean number of sensitized allergens in the control, $\mathrm{AH}, \mathrm{TH}$, and $\mathrm{ATH}$ groups was 3.0, $2.3,1.5$, and 1.2 , respectively. The mean was somewhat higher in the control group than in the other groups, but the difference was not significant. The prevalence of atopy in the control, $\mathrm{AH}, \mathrm{TH}$, and $\mathrm{ATH}$ groups was 50.0, 77.8, 68.4, and 42.9\%, respectively. The higher prevalence of atopy in the $\mathrm{AH}$ group than in the other groups was also not statistically significant.

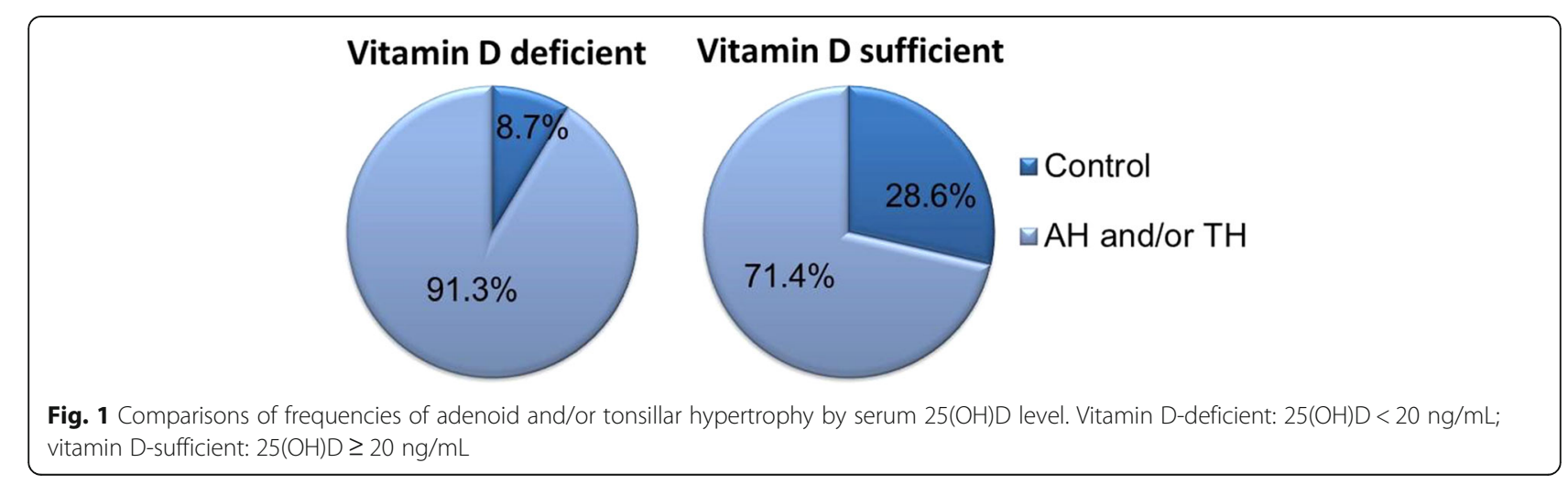


Table 1 Characteristics of 88 children with or without adenoid and/or tonsillar hypertrophy

\begin{tabular}{lllll}
\hline & $\begin{array}{l}\text { Control } \\
(N=16)\end{array}$ & $\begin{array}{l}\text { Adenoid hypertrophy } \\
(N=18)\end{array}$ & $\begin{array}{l}\text { Tonsillar hypertrophy } \\
(N=19)\end{array}$ & $\begin{array}{l}\text { Adenotonsillar hypertrophy } \\
(N=35)\end{array}$ \\
\hline Age (years) & $9.0 \pm 2.3$ & $10.9 \pm 1.5^{*}$ & $8.9 \pm 2.1$ & $7.8 \pm 2.9$ \\
Gender (male, \%) & $14(87.5 \%)^{*}$ & $14(77.8 \%)^{*}$ & $13(68.4 \%)$ & $18(51.4 \%)$ \\
Height (cm) & $136.7 \pm 14.2$ & $141.5 \pm 23.9$ & $137.8 \pm 14.9$ & $126.5 \pm 21.5$ \\
Weight $(\mathrm{kg})$ & $35.3 \pm 13.3$ & $42.2 \pm 24.4$ & $40.1 \pm 15.9$ & $31.7 \pm 18.8$ \\
BMl $\left(\mathrm{kg} / \mathrm{m}^{2}\right)$ & $18.2 \pm 3.3$ & $19.6 \pm 3.8$ & $20.3 \pm 4.1$ & $18.2 \pm 4.4$ \\
BMl z-score & $0.1 \pm 1.1$ & $0.5 \pm 0.8$ & $0.8 \pm 1.1$ & $0.3 \pm 1.1$ \\
25(OH)D & $22.5 \pm 4.3$ & $18.7 \pm 6.5$ & $19.4 \pm 4.5$ & $18.4 \pm 4.5$ \\
\hline
\end{tabular}

$B M I$ body mass index, 25(OH)D serum 25-hydroxy-vitamin $D$

*versus adenotonsillar hypertrophy group, $p<0.05$

Negative association of age, tonsil size, ANR, and height with serum 25(OH)D

We used Spearman's correlation test to explore correlations between the serum 25(OH)D level and other variables (Table 2). Age $(r=-0.26, p=0.001)$, tonsil size $(r=-0.46, p=0.002)$, ANR $(r=-0.40, p=0.001)$, and height $(r=-0.33, p=0.020)$ were negatively associated with the serum 25(OH)D level. Body weight, BMI, and BMI z-score also exhibited negative relationships, but these were not statistically significant.

\section{Marked association of tonsil size and ANR with serum 25(OH)D}

We used a multiple regression analysis to seek factors associated with vitamin D level (Table 3). In model 1, the serum $25(\mathrm{OH}) \mathrm{D}$ level was inversely associated with tonsil size $(\beta=-0.41, p=0.001)$, ANR $(\beta=-0.21$, $p=0.48)$, and BMI-z score $(\beta=-1.07, p=0.029)$ after adjusting for age and sex. These relationships persisted even after further adjustment in model 2 (tonsil size, $\beta=-0.40, \quad p=0.001 ; \quad$ ANR, $\quad \beta=-0.22, \quad p=0.043 ;$ and BMI-z score, $\beta=-1.07, p=0.001$ ).

\section{Discussion}

OSA is associated with an increased risk of vitamin D deficiency. Low vitamin D level increases the risk of OSA by promoting ATH, airway muscle myopathy, and/ or chronic rhinitis [23, 36-38]. Recent studies in adults showed that a large proportion of those with OSA also had a vitamin D deficiency [39, 40]. ATH is the most common cause of OSA in children. However, data on the relationship between vitamin $\mathrm{D}$ deficiency and $\mathrm{AH}$ and/or TH are conflicting [23-26]. In the present study, we used only winter data from children of the same ethnicity (Korean) living at the same latitude $\left(37^{\circ} 76^{\prime} \mathrm{N}\right)$ to control for contributions made by these factors to the extent of sunlight exposure. We found that the $25(\mathrm{OH}) \mathrm{D}$ level was reduced in children with $\mathrm{ATH}, \mathrm{AH}$, or TH. The sizes of the adenoids and tonsils, and BMI-z score predicted the serum $25(\mathrm{OH}) \mathrm{D}$ level.

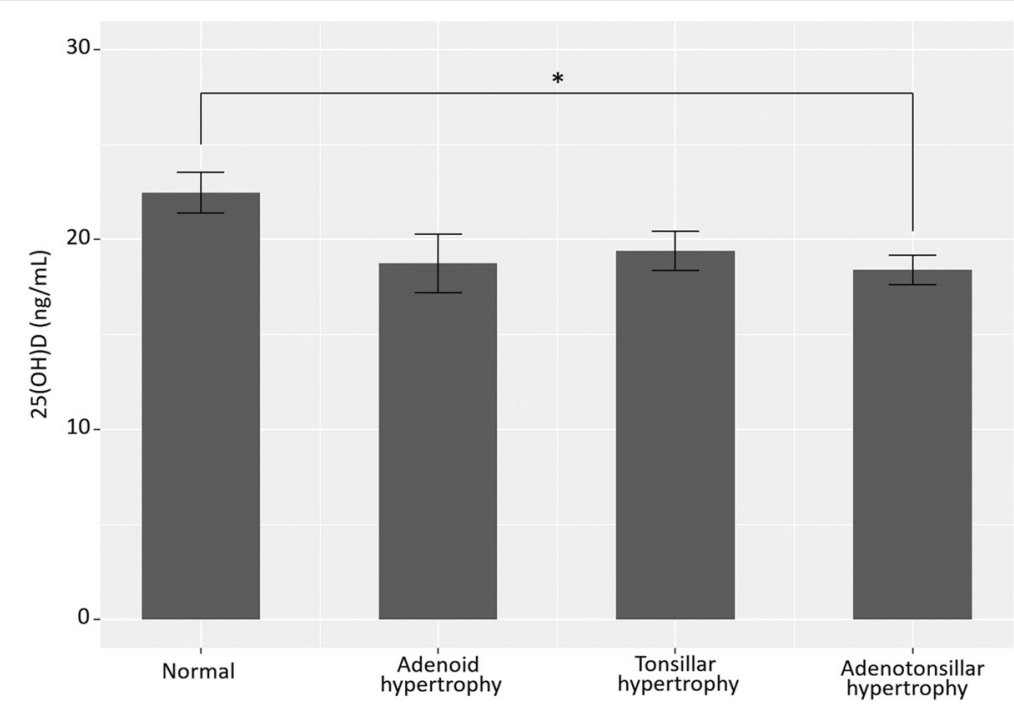

Fig. 2 Serum 25(OH)D levels in children with or without adenoid and/or tonsillar hypertrophy. ${ }^{*}: p<0.05$ 
Table 2 Correlation coefficients for serum 25(OH)D levels by Spearman's rank correlation rho

\begin{tabular}{lll}
\hline & $r$ value & $p$ value \\
\hline Age & $-0.26^{*}$ & 0.001 \\
Tonsil size & $-0.46^{*}$ & 0.002 \\
ANR & $-0.40^{*}$ & 0.001 \\
Height & $-0.33^{*}$ & 0.020 \\
Body weight & -0.26 & 0.060 \\
BMl & -0.16 & 0.270 \\
BMl z-score & -0.07 & 0.580 \\
The number of sensitized allergens & -0.08 & 0.61 \\
\hline
\end{tabular}

ANR adenoidal-nasopharyngeal ratio, BMI body mass index ${ }^{*} p<0.05$

We found that $52.3 \%$ of all children were vitamin D-deficient. In a nationwide Korean cross-sectional survey, the prevalence of vitamin $\mathrm{D}$ deficiency in randomly selected children was $18.4 \%$, thus lower than that in our study. However, the cited survey was conducted in autumn [41]. Another Korean study, conducted in autumn, winter, and spring, found that $59.1 \%$ of all children were vitamin $\mathrm{D}$-deficient [42]. These among-study differences are attributable to seasonal variations, participant age, and the prevalence of underlying conditions.

We found that the sizes of the tonsils and adenoids were negatively associated with the serum 25(OH)D level. Several studies have reported relationships between low vitamin D levels and adenotonsillar diseases $[23,24]$. A Turkish study found that children with recurrent tonsillitis and allergic rhinitis had significantly lower 1,25-dihydroxyvitamin D [1,25(OH)2D] levels than controls [24]. However, it was not clear that the low vitamin D levels were caused by the tonsillitis or allergic rhinitis, and the seasons in which blood samples were collected were not considered. A pilot study performed in the US found no difference in the vitamin D levels of children undergoing adenotonsillectomies and controls. However, the study included children who underwent adenotonsillectomies not only because of obstruction but also to treat recurrent infections. Again, the seasons in which blood was collected were not reported [25]. As mentioned above, these conflicting results may be explained by differences in latitude, season, ethnicity, and skin pigmentation $[6,29]$.

Vitamin D deficiency may increase ATH via inadequate regulation of the immune system. Vitamin $D$ receptors are found on T cells, B cells, antigen-presenting cells, macrophages, and dendritic cells. Vitamin D immunomodulates both innate and adaptive immune responses $[18,43]$. In terms of the innate immune system, vitamin $\mathrm{D}$ increases the production of antimicrobial peptides, including defensin $\beta$ and cathelicidin [44, 45]. In the adaptive immune system, the vitamin D inhibits the proliferation of activated lymphocytes, reduces the production of inflammatory cytokines, and promotes the development of induced regulatory $T$ cells [46-48]. Vitamin D deficiency increases the risk of upper and lower airway infections $[49,50]$. Many studies have shown that low vitamin D levels are associated with respiratory tract infections and that vitamin D supplements exert beneficial effects during the treatment of infectious diseases [51, 52], although some randomized controlled trials found that vitamin $\mathrm{D}$ afforded no benefit in those treated for infectious diseases [53-55]. A recent systematic review and meta-analysis reported that vitamin $\mathrm{D}$ supplements had a protective effect against acute respiratory infection, particularly in patients with profound vitamin D deficiency [12]. In terms of the effects of the vitamin $\mathrm{D}$ on the adenoids and tonsils, a deficiency may increase recurrent infections. In addition, vitamin $\mathrm{D}$ regulates human tonsillar $\mathrm{T}$ cells and a deficiency may trigger $\mathrm{TH}[18,56]$. Interestingly, recent studies suggested that low vitamin D levels are the result rather than the cause of the inflammatory process, as bacterial infection may induce the intracellular conversion of $25(\mathrm{OH}) \mathrm{D}$ to $1,25(\mathrm{OH}) 2 \mathrm{D}$, resulting in high $1,25(\mathrm{OH}) 2 \mathrm{D}$ and low 25(OH)D [57-59]. Therefore, the low vitamin D levels in ATH patients may be a consequence of recurrent adenotonsillitis by bacterial infections.

Many studies have found that increased BMI is associated with vitamin D insufficiency in children [60, 61].

Table 3 Multiple regression models of serum 25(OH)D level

\begin{tabular}{|c|c|c|c|c|c|c|}
\hline \multirow[t]{2}{*}{ Parameter } & \multicolumn{3}{|l|}{ Model $1^{a}$} & \multicolumn{3}{|l|}{ Model $2^{b}$} \\
\hline & Adjusted OR & $95 \% \mathrm{Cl}$ & $p$ value & Adjusted OR & $95 \% \mathrm{Cl}$ & $p$ value \\
\hline Height & -0.40 & $-1.35 \sim 0.54$ & 0.408 & & & \\
\hline Sensitization to mites & -0.13 & $-0.33 \sim 0.08$ & 0.238 & & & \\
\hline Tonsil size & -0.41 & $-0.63 \sim-0.19$ & 0.001 & -0.40 & $-0.62 \sim-0.18$ & 0.001 \\
\hline ANR & -0.21 & $-0.43 \sim-0.01$ & 0.048 & -0.22 & $-0.43 \sim-0.11$ & 0.043 \\
\hline BMI-z score & -1.07 & $-2.38 \sim-0.23$ & 0.029 & -1.07 & $-1.56 \sim-0.58$ & 0.001 \\
\hline
\end{tabular}

$O R$ odds ratio, $C l$ confidence interval, $A N R$ adenoidal-nasopharyngeal ratio, $B M I$ body mass index

${ }^{a}$ Adjusted for age and sex

${ }^{\mathrm{b}}$ Adjusted for age, sex, height and sensitization to mites 
Holick et al. [35] reported that the bioavailability of vitamin D in obesity was reduced because the vitamin was deposited in the body fat. The 2003-2006 USA National Health and Nutrition Examination Survey (which assessed children and adolescents) found that vitamin D deficiency was very prevalent in overweight and obese children [62]. A study of Korean children also revealed that the 25(OH)D level was lower in an overweight compared to a normal-weight group [63]. Consistent with the results of these previous studies, we found that the BMI-z score was negatively associated with the serum 25(OH)D level.

In terms of allergen sensitization, we found no significant difference in either the numbers of allergens to which children were sensitized or the prevalence of atopy among the four groups. Two explanations are possible. One is that the sensitivity of the MAST is low. The other is that children with both allergic rhinitis and turbinate hypertrophy were excluded. Thus, not all children with allergic rhinitis were included. Many studies have found that low vitamin D levels are associated with childhood allergic diseases, including allergic rhinitis, asthma, and atopic dermatitis [64, 65]. A recent Australian study found that a low vitamin D level in early childhood was associated with an increased risk of asthma and early allergic sensitization [65]. In Korea, a recent study showed that low vitamin D levels were associated with symptoms of allergic rhinitis and atopic dermatitis [41]. However, some studies yielded different results [66, 67]. A study of two large birth cohorts found that vitamin $\mathrm{D}$ had no protective effect against asthma or allergic rhinitis, and was positively associated with eczema, in 10-year-old children [66]. Thus, no conclusive association has been demonstrated between vitamin D and allergic disease.

A strength of our study is that it was conducted during one season in children of the same ethnicity and living at the same latitude. We thus controlled for several possible confounders. Second, we evaluated allergen sensitization patterns; other similar studies did not [20, 25]. Many studies have reported associations between vitamin D levels and allergic diseases [68, 69]; an evaluation of atopic status is essential when studying the effects of variations in vitamin D levels. Third, we defined clinical features predictive of vitamin D deficiency. Physicians can easily measure the sizes of the tonsils and adenoids, body weight, and BMI in children with SDB.

However, there are some limitations to our study. First, the sample size was too small to allow detailed generalizations to be made. Second, we did not use polysomnography (PSG) for the evaluation of SDB. However, although PSG is the gold standard for the diagnosis of $\mathrm{SDB}$, in practice, the test is time-consuming and cannot be easily performed in all patients. A study in the USA showed that only $10 \%$ of children who underwent adenotonsillectomy also underwent a PSG evaluation [70]. In addition, Franco et al. reported that OSA-18 scores correlated significantly with the respiratory distress index determined by PSG [31]. We used the KOSA-18 score [30] as one of the inclusion criteria in our study and included children whose health-related quality of life was moderately to severely affected by OSA. Third, we used the MAST rather than the skin prick test (SPT). However, although the SPT remains a major diagnostic tool, the MAST has the advantage that many allergens can be tested simultaneously. Also, MAST data correlate well with those of the SPT in rhinitis patients, which suggests that the MAST can serve as an alternative to the SPT [71]. Finally, we performed only a retrospective chart review. Additional, larger studies incorporating polysomnographic data may be required before general conclusions can be drawn.

\section{Conclusions}

Approximately half of all children with SDB were vitamin D-deficient. The sizes of the adenoids and tonsils, and BMI-z score were negatively associated with the serum 25(OH)D level. Our results suggest that SDB children with vitamin $\mathrm{D}$ deficiencies may need to be evaluated in terms of $\mathrm{AH}$ and/or $\mathrm{TH}$, and vice versa.

\section{Abbreviations \\ 1,25(OH)2D: 1,25-dihydroxyvitamin-D; 25(OH)D: Serum 25-hydroxy-vitamin D; AH: Adenoidal hypertrophy; ANR: Adenoidal-nasopharyngeal ratio; ATH: Adenotonsillar hypertrophy; BMI: Body mass index; KOSA-18 survey: Korean version of the obstructive sleep apnea-18 survey; MAST: Multiple allergen simultaneous test; OSA: Obstructive sleep apnea; PSG: Polysomnography; SDB: Sleep-disordered breathing; SPT: Skin prick test; TH: Tonsillar hypertrophy}

Acknowledgements

We thank Dr. Daeyoung Roh for contributing to the statistical analysis.

Availability of data and materials

The datasets used and/or analysed during the current study are available from the corresponding author on reasonable request.

\section{Authors' contributions \\ JHS and BGK conceived and designed the study. JHS, BYK and HK contributed to acquisition of the data. JHS, BYK, SWhK and SWoK analyzed and interpreted the data. JHS drafted and revised the manuscript. All authors involved in drafting the manuscript or revising it and approved the final manuscript.}

\section{Ethics approval and consent to participate}

The study protocol was approved by the Institutional Review Board of Uijeongbu St. Mary's Hospital (IRB policy No. UC15RISI0035). Since this study is a retrospective chart review study the need for written consent was formally waved by the IRB of Uijeongbu St. Mary's Hospital.

Consent for publication

Not applicable

Competing interests

The authors declare that they have no competing interests. 


\section{Publisher's Note}

Springer Nature remains neutral with regard to jurisdictional claims in published maps and institutional affiliations.

Received: 24 July 2017 Accepted: 14 June 2018

Published online: 19 June 2018

\section{References}

1. Kobayashi R, Miyazaki S, Karaki M, Hoshikawa H, Nakata S, Hara H, et al. Obstructive sleep apnea in Asian primary school children. Sleep Breath. 2014;18:483-9.

2. Kaditis AG, Alonso Alvarez ML, Boudewyns A, Alexopoulos El, Ersu R, Joosten $\mathrm{K}$, et al. Obstructive sleep disordered breathing in 2- to 18-year-old children: diagnosis and management. Eur Respir J. 2016;47:69-94.

3. Sedky K, Bennett DS, Carvalho KS. Attention deficit hyperactivity disorder and sleep disordered breathing in pediatric populations: a meta-analysis. Sleep Med Rev. 2014;18:349-56.

4. Waters KA, Chawla J, Harris MA, Dakin C, Heussler H, Black R, et al. Rationale for and design of the "POSTA" study: evaluation of neurocognitive outcomes after immediate adenotonsillectomy compared to watchful waiting in preschool children. BMC Pediatr. 2017;17:47.

5. Bouillon R. Comparative analysis of nutritional guidelines for vitamin D. Nat Rev Endocrinol. 2017;13:466-79

6. Wacker M, Holick MF. Sunlight and Vitamin D: a global perspective for health. Dermatoendocrinol. 2013;5:51-108.

7. Ariganjoye R. Pediatric Hypovitaminosis D: molecular perspectives and clinical implications. Glob Pediatr Health. 2017; https://doi.org/10.1177/ $2333794 \times 16685504$

8. Akbar NA, Zacharek MA. Vitamin D: immunomodulation of asthma, allergic rhinitis, and chronic rhinosinusitis. Curr Opin Otolaryngol Head Neck Surg. 2011:19:224-8

9. Carroll WW, Schlosser RJ, O'Connell BP, Soler ZM, Mulligan JK. Vitamin D deficiency is associated with increased human sinonasal fibroblast proliferation in chronic rhinosinusitis with nasal polyps. Int Forum Allergy Rhinol. 2016:6:605-10.

10. Walker RE, Bartley J, Camargo CA Jr, Flint D, Thompson JMD, Mitchell EA. Higher serum 25(OH)D concentration is associated with lower risk of chronic otitis media with effusion: a case-control study. Acta Paediatr. 2017; 106(9):1487-92.

11. Lee $\mathrm{SB}$, Lee $\mathrm{CH}, \mathrm{Kim}$ YJ, Kim HM. Biochemical markers of bone turnover in benign paroxysmal positional vertigo. PLoS One. 2017;12:e0176011.

12. Martineau AR, Jolliffe DA, Hooper RL, Greenberg L, Aloia JF, Bergman P, et al. Vitamin D supplementation to prevent acute respiratory tract infections: systematic review and meta-analysis of individual participant data. BMJ. 2017;356:i6583.

13. Martineau AR, Cates CJ, Urashima M, Jensen M, Griffiths AP, Nurmatov U, et al. Vitamin D for the management of asthma. Cochrane Database Syst Rev. 2016:9:Cd011511.

14. Ozgurhan G, Vehapoglu A, Vermezoglu O, Temiz RN, Guney A, Hacihamdioglu B. Risk assessment of obstructive sleep apnea syndrome in pediatric patients with vitamin D deficiency: a questionnaire-based study. Medicine (Baltimore). 2016;95:e4632.

15. Zicari AM, Occasi F, Di Mauro F, Lollobrigida V, Di Fraia M, Savastano V, et al. Mean platelet volume, vitamin $D$ and $C$ reactive protein levels in normal weight children with primary snoring and obstructive sleep apnea syndrome. PLoS One. 2016;11(4):e0152497.

16. Liguori C, Izzi F, Mercuri NB, Romigi A, Cordella A, Tarantino U, et al. Vitamin D status of male OSAS patients improved after long-term CPAP treatment mainly in obese subjects. Sleep Med. 2017;29:81-5.

17. Liguori C, Romigi A, Izzi F, Mercuri NB, Cordella A, Tarquini E, et al. Continuous positive airway pressure treatment increases serum vitamin $D$ levels in male patients with obstructive sleep apnea. J Clin Sleep Med. 2015;11(6):603-7.

18. McCarty DE, Chesson AL Jr, Jain SK, Marino AA. The link between vitamin D metabolism and sleep medicine. Sleep Med Rev. 2014;18:311-9.

19. Bozkurt NC, Cakal E, Sahin M, Ozkaya EC, Firat H, Delibasi T. The relation of serum 25-hydroxyvitamin-D levels with severity of obstructive sleep apnea and glucose metabolism abnormalities. Endocrine. 2012;41:518-25.

20. Kheirandish-Gozal L, Peris E, Gozal D. Vitamin D levels and obstructive sleep apnoea in children. Sleep Med. 2014;15:459-63.

21. Reid D, Toole BJ, Knox S, Talwar D, Harten J, O'Reilly DS, et al. The relation between acute changes in the systemic inflammatory response and plasma 25-hydroxyvitamin D concentrations after elective knee arthroplasty. Am J Clin Nutr. 2011:93(5):1006-11.

22. Henriksen VT, Rogers VE, Rasmussen GL, Trawick RH, Momberger NG, Aguirre D, et al. Pro-inflammatory cytokines mediate the decrease in serum 25(OH)D concentrations after total knee arthroplasty? Med Hypotheses. 2014;82(2):134-7.

23. Reid D, Morton R, Salkeld L, Bartley J. Vitamin D and tonsil diseasepreliminary observations. Int J Pediatr Otorhinolaryngol. 2011;75:261-4

24. San T, Muluk NB, Cingi C. 1,25(OH)(2)D-3 and specific lgE levels in children with recurrent tonsillitis, and allergic rhinitis. Int J Pediatr Otorhinolaryngol. 2013;77:1506-11.

25. Esteitie R, Naclerio RM, Baroody FM. Vitamin D levels in children undergoing adenotonsillectomies. Int J Pediatr Otorhinolaryngol. 2010;74:1075-7.

26. Aydın S, Aslan I, Yıldız I, Ağaçhan B, Toptaş B, Toprak S, et al. Vitamin D levels in children with recurrent tonsillitis. Int J Pediatr Otorhinolaryngol. 2011;75:364-7

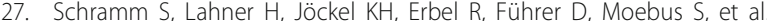
Impact of season and different vitamin $D$ thresholds on prevalence of vitamin D deficiency in epidemiological cohorts-a note of caution. Endocrine. 2017;56:658-66.

28. Fuleihan Gel H, Bouillon R, Clarke B, Chakhtoura M, Cooper C, McClung M, et al. Serum 25-Hydroxyvitamin D levels: variability, knowledge gaps, and the concept of a desirable range. J Bone Miner Res. 2015;30:1119-33.

29. Mazahery $H$, von Hurst PR. Factors affecting 25 -Hydroxyvitamin D concentration in response to vitamin D supplementation. Nutrients. 2015;7:5111-42.

30. Park CS, Guilleminault C, Hwang SH, Jeong JH, Park DS, Maeng JH. Correlation of salivary cortisol level with obstructive sleep apnea syndrome in pediatric subjects. Sleep Med. 2013;14(10):978-84.

31. Franco RA Jr, Rosenfeld RM, Rao M. First place-resident clinical science award 1999. Quality of life for children with obstructive sleep apnea. Otolaryngol Head Neck Surg. 2000;123:9-16.

32. Brodsky L, Moore L, Stanievich JF. A comparison of tonsillar size and oropharyngeal dimensions in children with obstructive adenotonsillar hypertrophy. Int J Pediatr Otorhinolaryngol. 1987;13:149-56.

33. Fujioka M, Young LW, Girdany BR. Radiographic evaluation of adenoidal size in children: adenoidal-nasopharyngeal ratio. AJR Am J Roentgenol. 1979;133:401-4.

34. Nepper-Christensen S, Backer V, DuBuske LM, Nolte H. In vitro diagnostic evaluation of patients with inhalant allergies: summary of probability outcomes comparing results of CLA- and CAP-specific immunoglobulin E test systems. Allergy Asthma Proc. 2003;24:253-8.

35. Holick MF, Chen TC. Vitamin D deficiency: a worldwide problem with health consequences. Am J Clin Nutr. 2008;87:1080S-6S.

36. Atan Sahin O, Kececioglu N, Serdar M, Ozpinar A. The association of residential mold exposure and adenotonsillar hypertrophy in children living in damp environments. Int J Pediatr Otorhinolaryngol. 2016;88:233-8.

37. Dogru M, Suleyman A. Serum 25-hydroxyvitamin D3 levels in children with allergic or nonallergic rhinitis. Int J Pediatr Otorhinolaryngol. 2016;80:39-42.

38. Prabhala A, Garg R, Dandona P. Severe myopathy associated with vitamin D deficiency in western New York. Arch Intern Med. 2000;160(8):1199-203.

39. Piovezan RD, Hirotsu C, Feres MC, Cintra FD, Andersen ML, Tufik S, et al. Obstructive sleep apnea and objective short sleep duration are independently associated with the risk of serum vitamin D deficiency. PLoS One. 2017:12(7):e0180901.

40. Salepci B, Caglayan B, Nahid P, Parmaksiz ET, Kiral N, Fidan A, et al. Vitamin $D$ deficiency in patients referred for evaluation of obstructive sleep apnea. J Clin Sleep Med. 2017;13(4):607-12.

41. Yang HK, Choi J, Kim WK, Lee SY, Park YM, Han MY, et al. The association between hypovitaminosis $D$ and pediatric allergic diseases: a Korean nationwide population-based study. Allergy Asthma Proc. 2016;37:64-9.

42. Roh YE, Kim BR, Choi WB, Kim YM, Cho MJ, Kim HY, et al. Vitamin D deficiency in children aged 6 to 12 years: single center's experience in Busan. Ann Pediatr Endocrinol Metab. 2016:21:149-54.

43. Rosendahl J, Holmlund-Suila E, Helve O, Viljakainen $\mathrm{H}$, Hauta-Alus $\mathrm{H}$, Valkama $\mathrm{S}$, et al. 25-hydroxyvitamin D correlates with inflammatory markers in cord blood of healthy newborns. Pediatr Res. 2017;81(5):731-5.

44. Liu PT, Stenger S, Li H, Wenzel L, Tan BH, Krutzik SR, et al. Toll-like receptor triggering of a vitamin D-mediated human antimicrobial response. Science. 2006:311(5768):1770-3.

45. Wang TT, Nestel FP, Bourdeau V, Nagai Y, Wang Q, Liao J, et al. Cutting edge: 1,25-dihydroxyvitamin D3 is a direct inducer of antimicrobial peptide gene expression. J Immunol. 2004;173(5):2909-12. 
46. Xie Z, Chen J, Zheng C, Wu J, Cheng Y, Zhu S, et al. 1,25-dihydroxyvitamin Dinduced dendritic cells suppress experimental autoimmune encephalomyelitis by increasing proportions of the regulatory lymphocytes and reducing $T$ helper type 1 and type 17 cells. Immunology. 2017;152(3):414-24.

47. Mansouri L, Lundwall K, Moshfegh A, Jacobson SH, Lundahl J, Spaak J. Vitamin D receptor activation reduces inflammatory cytokines and plasma MicroRNAs in moderate chronic kidney disease - a randomized trial. BMC Nephrol. 2017;18(1):161.

48. Zhou Q, Qin S, Zhang J, Zhon L, Pen Z, Xing T. 1,25(OH)2D3 induces regulatory $T$ cell differentiation by influencing the VDR/PLC- $\gamma 1 / T G F-\beta 1 /$ pathway. Mol Immunol. 2017;91:156-64.

49. Ginde AA, Mansbach JM, Camargo CA Jr. Vitamin D, respiratory infections, and asthma. Curr Allergy Asthma Rep. 2009;9:81-7.

50. Mora JR, Iwata M, von Andrian UH. Vitamin effects on the immune system: vitamins a and D take Centre stage. Nat Rev Immunol. 2008;8:685-98.

51. Ginde AA, Mansbach JM, Camargo CA Jr. Association between serum 25hydroxyvitamin D level and upper respiratory tract infection in the third National Health and nutrition examination survey. Arch Intern Med. 2009:169:384-90.

52. Ginde AA, Blatchford P, Breese K, Zarrabi L, Linnebur SA, Wallace Il, et al. High-dose monthly vitamin $D$ for prevention of acute respiratory infection in older long-term care residents: a randomized clinical trial. J Am Geriatr Soc. 2017;65(3):496-503.

53. Rees JR, Hendricks K, Barry EL, Peacock JL, Mott LA, Sandler RS, et al. Vitamin D3 supplementation and upper respiratory tract infections in a randomized, controlled trial. Clin Infect Dis. 2013;57(10):1384-92.

54. Li-Ng M, Aloia JF, Pollack S, Cunha BA, Mikhail M, Yeh J, et al. A randomized controlled trial of vitamin D3 supplementation for the prevention of symptomatic upper respiratory tract infections. Epidemiol Infect. 2009:137:1396-404.

55. Somnath SH, Biswal N, Chandrasekaran V, Jagadisan B, Bobby Z. Therapeutic effect of vitamin $D$ in acute lower respiratory infection: a randomized controlled trial. Clin Nutr ESPEN. 2017;20:24-8.

56. Nunn JD, Katz DR, Barker $\mathrm{S}$, et al. Regulation of human tonsillar T-cell proliferation by the active metabolite of vitamin D3. Immunology. 1986;59:479-84.

57. Mangin M, Sinha R, Fincher K. Inflammation and vitamin D: the infection connection. Inflamm Res. 2014;63(10):803-19.

58. Waldron JL, Ashby HL, Cornes MP, Bechervaise J, Razavi C, Thomas OL, et al Vitamin D: a negative acute phase reactant. J Clin Pathol. 2013;66(7):620-2.

59. Custódio G, Schwarz P, Crispim D, Moraes RB, Czepielewski M, Leitão CB, et al. Association between vitamin $\mathrm{D}$ levels and inflammatory activity in brain death: a prospective study. Transpl Immunol. 2018; https://doi.org/10.1016/j. trim.2018.02.014. Epub ahead of print

60. Szlagatys-Sidorkiewicz A, Brzezinski M, Jankowska A, Metelska P, SlominskaFraczek M, Socha $P$. Long-term effects of vitamin D supplementation in vitamin D deficient obese children participating in an integrated weightloss programme (a double-blind placebo-controlled study) - rationale for the study design. BMC Pediatr. 2017;17:97.

61. Barja-Fernández S, Aguilera CM, Martínez-Silva I, Vazquez R, Gil-Campos M, Olza J, et al. 25-Hydroxyvitamin D levels of children are inversely related to adiposity assessed by body mass index. J Physiol Biochem. 2018;74(1):111-8.

62. Turer $\mathrm{CB}$, Lin $\mathrm{H}$, Flores $\mathrm{G}$. Prevalence of vitamin D deficiency among overweight and obese US children. Pediatrics. 2013;131:e152-61.

63. Chung $\mathbb{H}$, Kim HJ, Chung S, Yoo EG. Vitamin D deficiency in Korean children: prevalence, risk factors, and the relationship with parathyroid hormone levels. Ann Pediatr Endocrinol Metab. 2014;19:86-90.

64. Aryan Z, Rezaei N, Camargo CA Jr. Vitamin D status, aeroallergen sensitization, and allergic rhinitis: a systematic review and meta-analysis. Int Rev Immunol. 2017;36:41-53.

65. Hollams EM, Teo SM, Kusel M, et al. Vitamin D over the first decade and susceptibility to childhood allergy and asthma. J Allergy Clin Immunol. 2017;139:472-81.

66. Wawro N, Heinrich J, Thiering E, Kratzsch J, Schaaf B, Hoffmann B, et al. Serum 25(OH)D concentrations and atopic diseases at age 10: results from the GINIplus and LISAplus birth cohort studies. BMC Pediatr. 2014;14:286.

67. Cairncross C, Grant C, Stonehouse W, Conlon C, McDonald B, Houghton L, et al. The relationship between vitamin $D$ status and allergic diseases in New Zealand preschool children. Nutrients. 2016;8:6.

68. Arikoglu T, Kuyucu S, Karaismailoglu E, Batmaz SB, Balci S. The association of vitamin D, cathelicidin, and vitamin D binding protein with acute asthma attacks in children. Allergy Asthma Proc. 2015;36(4):51-8.
69. Chiu CY, Su KW, Tsai MH, Hua MC, Liao SL, Lai SH, et al. Longitudinal vitamin $\mathrm{D}$ deficiency is inversely related to mite sensitization in early childhood. Pediatr Allergy Immunol. 2017; https://doi.org/10.1111/pai.12846. Epub ahead of print

70. Mitchell RB, Pereira KD, Friedman NR. Sleep-disordered breathing in children: survey of current practice. Laryngoscope. 2006;116:956-8.

71. Cho JH, Suh JD, Kim JK, Hong SC, Park IH, Lee HM. Correlation between skin-prick testing, individual specific lgE tests, and a multiallergen IgE assay for allergy detection in patients with chronic rhinitis. Am J Rhinol Allergy. 2014;28:388-91.

\section{Ready to submit your research? Choose BMC and benefit from:}

- fast, convenient online submission

- thorough peer review by experienced researchers in your field

- rapid publication on acceptance

- support for research data, including large and complex data types

- gold Open Access which fosters wider collaboration and increased citations

- maximum visibility for your research: over $100 \mathrm{M}$ website views per year

At BMC, research is always in progress.

Learn more biomedcentral.com/submissions 